\title{
A noção de gramática em Saussure
}

Aline Moretto Costa ${ }^{1}$

Luiza Milano ${ }^{2}$

\section{Resumo}

Este texto apresenta e desenvolve a ideia acerca da noção de gramática em Saussure, a partir de três princípios fundamentais, a saber, a arbitrariedade, o valor e o mecanismo linguistico. Nosso objetivo é mostrar como esses três princípios fundam um conceito de gramática em Saussure. Inicialmente, discorremos sobre o desenvolvimento do pensamento do mestre ao resolver um problema metodológico a partir dos dois primeiros principios - arbitrariedade e valor. A partir de nossa leitura do Curso de linguística geral depreendemos essas noções, as quais nos levam a concluir que é no uso que veremos o funcionamento da língua. Por fim, mostramos como arbitrariedade e valor estão em jogo no mecanismo linguístico. Entendemos que a analogia, um dos fenômenos que explica o mecanismo linguístico, é o grande exemplo de como o sujeito falante e a própria noção de fala estão presentes na perspectiva saussuriana. A concepção de gramática em Saussure decorre, portanto, desses três grandes principios que se inter-relacionam.

Palavras-chave: Arbitrariedade. Epistemologia da linguística. Gramática. Mecanismo. Valor linguistico

\footnotetext{
${ }^{1}$ Licenciada em Letras Português-Espanhol pela Universidade Federal do Rio Grande do Sul. Mestranda em Estudos da Linguagem.

${ }^{2}$ Graduada em Fonoaudiologia pela Universidade Federal de Santa Maria. Mestra e Doutora em Letras pela Universidade Federal do Rio Grande do Sul (UFRGS). Professora do Departamento de Letras Clássicas e Vernáculas do Instituto de Letras da UFRGS e professora e orientadora do Programa de Pós-graduação em Letras da mesma Universidade.
} 


\title{
Introdução
}

Isaac Nicolau Salum, no prefácio à edição brasileira do Cours de linguistique générale, comenta que "Nunca Saussure esteve mais presente do que nesta década, em que ele é às vezes declarado "superado"' (SAUSSURE, 1974 p. XV). Esse enunciado foi escrito meio século após a primeira edição do $C L G^{3}$, e ele poderia, indubitavelmente, ser proferido outra vez em nossa década; não com o mesmo valor que teve na primeira edição traduzida para o português - já que hoje, cem anos após a publicação do CLG, temos mais acesso não só a esse texto, mas a uma significativa fortuna crítica que o acompanha. Como afirma Normand (2009), é necessário ler atentamente essa "berança histórica", e como destaca Benveniste (1991, p. 34), "Não há um só linguista hoje que não lhe deva algo. Não há uma só teoria geral que não mencione o seu nome”. Não ler e não reconhecer Saussure como o responsável por transformar o fazer dos linguistas e, portanto, alterar a Linguística, é extremamente complicado.

Dessa forma, não podemos afirmar (e provavelmente nunca poderemos) que Saussure está superado, dado o número de estudos e de publicações recentes sobre a sua teoria linguística. Não podemos negar, portanto, que os princípios apresentados no pensamento saussuriano são o fundamento de diversas teorias linguísticas; cada uma - a partir de reflexões do linguista genebrino - encaminha a sua própria reflexão sobre língua e linguagem. É, nesse sentido, que para estudá-lo, hoje, cabe-nos especificar que Saussure se estuda. Isto posto, pensamos Saussure no âmbito de uma epistemologia da linguística, já que o filólogo pensava o fazer do linguista nestes termos. Dessa forma, pensar sobre o que o linguista faz é necessariamente demarcar uma metodologia:

\begin{abstract}
Mas, reciprocamente, o estudo das línguas existentes se condenaria a permanecer quase estéril, a permanecer, em todo caso, desprovido, ao mesmo tempo, de método e de qualquer princípio diretor, se não tendesse constantemente a esclarecer o problema geral da linguagem, se não procurasse destacar, de cada fato particular que observa, o sentido e o proveito claro que dele resultam para o conhecimento que temos das operações possíveis do instinto humano aplicado à língua (SAUSSURE, 2004, p. 129, grifos nossos).
\end{abstract}

E isso é o que Saussure se propôs a fazer nos cursos de linguística geral que ministrou. A despeito de ter publicado muito pouco em vida a respeito de suas ideias, ele é o primeiro a fazer um mapeamento epistemológico, trazendo um rigor científico a partir de

\footnotetext{
${ }^{3}$ Utilizaremos a sigla ao longo do trabalho para nos referirmos à edição brasileira do Curso de Linguística Geral.
} 
questões/pensamentos levantados para fundamentar uma ciência linguística.

E ainda que a pergunta de Saussure seja filosófica, "Mas o que é a língua?", as respostas que ele traz são epistemológicas/metodológicas. Isso é evidente quando nos deparamos com a terceira tarefa da linguística: delimitar-se e definir-se a si própria, ou seja, fazer ciência. E para tanto foi necessário que Saussure definisse língua e linguagem; sendo esta, conforme o linguista genebrino - constituindo fator mais importante que qualquer outro na vida dos indivíduos e das sociedades - “[...] multiforme e heteróclita: a cavaleiro de diferentes domínios, ao mesmo tempo física, fisiológica e psíquica, ela pertence, além disso, ao domínio individual e ao domínio social" (SAUSSURE, 1974, p. 17), e não podemos classificá-la em nenhuma categoria de fatos humanos, já que não sabemos como deduzir sua unidade; e aquela, sendo somente uma parte determinada, essencial - sem dúvida - da linguagem. Língua é, para Saussure, "um sistema de signos que exprimem ideias" (SAUSSURE, 1974, p. 24), sendo o signo linguístico, portanto, sua unidade. A língua é uma instituição social, mas não como as outras; é através dela que se constata o inapreensível do mundo, e é natural ao homem a faculdade de constituir uma língua; a língua é, dessa forma, o objeto da Linguística.

É a partir de uma preocupação metodológica, que o filólogo, então, traz um conjunto de princípios que regem o funcionamento de uma língua, vale dizer, um conceito de gramática. Segundo Normand, em seu livro "Saussure”,

[...] o Cours representa a única reflexão geral sobre a gramática comparada conforme à exigência da epistemologia positivista, sendo ao mesmo tempo muito mais do que isso. Reconhecer ali a realização da linguística geral era pôr em causa práticas bem mais ancoradas que ainda pareciam profícuas; era, em particular, reconhecer que seria necessário proceder de outro modo para recolher os dados que deviam conduzir a essa linguística geral; aceitar, pois, as consequências desses princípios abstratos (NORMAND, 2009, p. 91).

Nesse sentido, entendendo a língua como sistema de signos, é necessário partir do sistema e, portanto, não isolar as unidades, visto que elas só existem linguisticamente na forma de relações. O linguista genebrino critica o isolamento de elementos na gramática comparada, realizado pela linguística histórica e, em vista disso, postula uma noção desde uma perspectiva de língua em uso. Para tanto, Saussure ancora sua concepção de gramática - conforme apontaremos a seguir - em três princípios fundamentais: 1) a arbitrariedade, ou seja, qualquer elemento pode ligar-se a qualquer sentido, portanto não se trata de uma gramática normativa; 2) decorrente da primeira: a noção de valor, ou seja, qualquer signo na 
língua está na dependência de todos os outros que compõem o sistema; e 3) o mecanismo, porque só saberemos o valor de um elemento - que vai ser deliberado arbitrariamente através das relações que ele trava via mecanismo.

Nosso objetivo é, portanto, mostrar como esses três princípios fundam um conceito de gramática em Saussure. Em um primeiro momento, discutiremos como o linguista resolve um problema metodológico a partir dos princípios de arbitrariedade e valor. Após isso, mostraremos como esses princípios estão em jogo no mecanismo linguístico, que constituem o ponto onde o trabalho de Saussure toca os limites gramaticais e o lugar em que a natureza criativa da língua é posta em evidência.

Mesmo sabendo que se tem à disposição uma grande quantidade de textos que compõem o que se chama de corpus saussuriano (FLORES et al., 2013, p. 13) ${ }^{4}$, nosso ponto de partida será o clássico livro Curso de Linguística Geral (1974) - organizado por Charles Bally e Albert Sechehaye. Utilizaremos também, como baliza para trilhar nosso percurso, alguns fragmentos do também traduzido no Brasil Escritos de Linguística Geral (2004) organizado e editado por Simon Bouquet e Rudolf Engler. O leitor perceberá ainda que consultaremos publicações de teóricos herdeiros do legado do mestre genebrino ${ }^{5}$.

\section{Arbitrariedade e valor: o desenvolvimento do pensamento saussuriano}

Inúmeras vezes Ferdinand de Saussure questionou-se sobre a unidade da língua, e essa é uma questão muito complexa, já que submetidas a ela, estão questões como a natureza da língua e da linguagem e a relação que estas estabelecem.

Para definir o signo linguístico como unidade o genebrino recorreu ao princípio da arbitrariedade. Saussure emprega signo, ao longo de seus manuscritos (e de suas aulas), como uma combinação composta de duas faces (como entidade linguística global),

\footnotetext{
${ }_{4}$ Temos, hoje, um amplo número de fontes de pesquisa que incluem o Curso de Linguística Geral, obras escritas e publicadas pelo próprio mestre genebrino, fontes manuscritas (não publicadas) de Saussure, cartas (pessoais ou profissionais, de alunos), anotações de alunos, edições críticas do Curso, os Anagramas, entre outros documentos que formam o que Flores et al. (2013) chama de corpus saussuriano. Por esse motivo, é necessário que se faça um recorte dessa infinidade de documentos que constituirão um corpus de pesquisa.

${ }^{5}$ Entre estes herdeiros estão incluídos autores como Roman Jakobson, Jean Starobinski, Simon Bouquet, Rudolf Engler, Claudine Normand, Françoise Gadet; linguistas que fizeram leituras e releituras do vasto número de fontes disponíveis.
} 
fonológica e conceitual. E será apenas no terceiro curso que o linguista genebrino fala nos termos significante/significado para explicar sobre a arbitrariedade do signo, como podemos depreender desta passagem no CLG:

Propomo-nos a conservar o termo signo para designar o total, e a substituir conceito e imagem acústica respectivamente por significado e significante; esses dois termos têm a vantagem de assinalar a oposição, que os separa, quer entre si, quer do total de que fazem parte. Quanto a signo, se nos contentamos com ele, é porque não sabemos por que substituí-lo, visto não nos sugerir a língua usual nenhum outro (SAUSSURE, 1974, p. 81, grifos do autor).

Fica evidente a associação entre um significante e um significado que é dado pelo princípio de arbitrariedade. Ao contrário do que comumente se entende pelo par como uma porção concreta e outra abstrata - ideia dada justamente pelos termos conceito e imagem acústica -, em Saussure tudo é abstração; no entanto, os linguistas precisam de entidades concretas (o signo) passíveis de serem recortadas - pelo valor - e analisadas. Gadet (1990) chama isso de o paradoxo da unidade concreta. Para entendermos melhor como essas questões são resolvidas por Saussure, temos de partir da discussão das entidades concretas da língua, título dado ao capítulo II da primeira parte em "Princípios Gerais" no CLG, e é justamente neste capítulo (e também no que segue sobre Identidades, Realidades e Valores que falaremos mais adiante quando tratarmos do mecanismo) que Saussure resolve um dos importantes problemas metodológicos da Linguística.

É necessário, antes, entendermos que para Saussure a língua é virtual; ela, de fato, só existe na fala, portanto colocada em uso, ou seja, é através da fala que temos a inferência do que seja a língua.

O significado e o significante, que são as duas faces do signo linguístico, são dois elementos de natureza distinta: um representa a ideia, o conceito; o outro a impressão causada por algo de natureza material. No entanto, cabe lembrar que, para Saussure, as duas faces do signo são consideradas abstrações. Existe uma confusão que é gerada com os exemplos do cavalo e da árvore - no capítulo dedicado ao signo linguístico - em que há o desenho de uma árvore no lugar da porção conceitual (significado). Lembremos que "O signo linguístico une, não uma coisa e uma palavra, mas um conceito e uma imagem acústica" (SAUSSURE, 1974, p. 80), substituídos mais adiante por significado e significante. Nessa passagem há um comentário/nota dos editores, explicando que "Para F. de Saussure, porém, a língua é essencialmente um depósito, uma coisa recebida de fora [...]. 
A imagem acústica é, por excelência, a representação natural da palavra enquanto fato de língua virtual, fora de toda a realização pela fala". Natural, neste caso, não significa ser biológico; e "palavra" seria a unidade utilizada praticamente em todo o CLG, mas que poderia ser qualquer outro signo linguístico ${ }^{6}$. Além disso, fala-se em língua virtual, reiterando que não se trata de um estado de coisas no mundo, mas sim de abstração. Em vista disso, entendemos que os desenhos que estão presentes no CLG da forma como são colocados (o desenho da árvore colocada dentro do esquema do signo linguístico não é encontrado em nenhum manuscrito do genebrino, nem nos cadernos dos alunos; trata-se de uma inserção feita pelos editores) não são os mais adequados para representarem o significado e o significante.

A língua é representação (virtual e depende da fala) e, portanto, a sua unidade - o signo - também o é; por essa razão, não há nenhuma relação natural com o mundo; o que existe é uma interpretação do mundo. É a partir dessa ideia que Saussure afirma que o signo linguístico é arbitrário. A arbitrariedade radical - ou seja, qualquer massa amorfa de sons pode ligar-se a qualquer sentido - é o laço que une um significante a um significado. Com isso, Saussure resolve um problema epistemológico, afastando-se da filosofia, por exemplo. A arbitrariedade é o que liga o significante ao significado, e é por esse princípio que podemos entender não só que a língua não muda, mas também que ela muda. É nesse paradoxo que encontramos a complexidade do pensamento saussuriano. A língua não muda, pois o significado não depende da livre escolha de quem fala, o signo está estabelecido num grupo linguístico (SAUSSURE, 1974), ele é atrelado, portanto, ao caráter social, a uma coletividade social; ademais, as sociedades conhecem a língua que lhes foi herdada das gerações anteriores (SAUSSURE, 1974, p. 86), e falamos da mesma forma como no dia anterior. No entanto, a língua também muda, visto que "o signo está em condições de alterar-se porque se continua” (SAUSSURE, 1974, p. 89), ou seja, a amarração significado-significante pode "afrouxar-se", havendo um deslocamento nessa relação.

$\mathrm{Na}$ segunda conferência dada por Saussure na Universidade de Genebra em novembro de 1891, o linguista deixa bastante clara sua visão sobre essa suposta

\footnotetext{
${ }^{6}$ Há uma passagem no CLG extremamente esclarecedora a esse respeito: "Não podendo captar diretamente as entidades concretas ou unidades da língua, trabalharemos sobre as palavras. Estas, sem recobrir exatamente a definição de unidade linguística, dão dela uma ideia pelo menos aproximada, que tem a vantagem de ser concreta; tomá-las-emos, pois, como espécimes equivalentes aos termos reais de um sistema sincrônico, e os princípios obtidos a propósito das palavras serão válidos para as entidades em geral" (SAUSSURE, 1974, p. 132).
} 
contradição:

Esses dois princípios, da continuidade e da mutabilidade da língua, longe de serem contraditórios, estão em correlação tão estreita e tão evidente que, quando temos vontade de menosprezar um deles, ofendemos o outro, ao mesmo tempo, e inevitavelmente, sem nem mesmo pensar nele.

Quem cede à primeira ilusão de se representar o francês como algo imóvel, no momento presente ou em outro qualquer, acaba forçosamente nada entendendo do que se passou no período entre os anos 500 e 900 . Então, supõe um salto: um salto antes de um parágrafo, um toque de varinha mágica, ou um parto inaudito, em que um idioma dá subitamente a vida a um outro idioma. Da mesma forma, quem começa por suprimir a ideia de continuidade, imaginando que um dia o francês saiu, como Minerva do cérebro de Júpiter, armado dos pés à cabeça, das entranhas da língua latina, cai regularmente no sofisma da imobilidade; essa pessoa supõe, naturalmente, que, entre dois desses saltos imaginários, a língua está em estado de equilíbrio e de repouso ou, ao menos, de um equilíbrio que se oponha a esses saltos, ao passo que não há jamais, na realidade, um equilíbrio, um ponto permanente, estável, em língua alguma (SAUSSURE, 2004, p. 137-138, grifos do autor).

Esse é o terreno que o $C L G$ prepara para mais adiante trazer a questão da analogia como parte do mecanismo linguístico: o princípio da arbitrariedade é o que permite que vejamos a analogia como um fenômeno que atesta não só a continuidade da língua, mas também seu caráter de renovação linguística. E isso só ocorre porque o fenômeno analógico está pautado pelo princípio de arbitrariedade do signo.

Vimos, então, que o arbitrário será a base para se entender o caráter simultaneamente concreto e abstrato da unidade com a qual lidam os linguistas. E a entidade se desvanece se retiver apenas o significado ou o significante, justamente porque ela é concebida do ponto de vista do falante, que não separa esses elementos jamais; no momento da fala tudo ocorre ao mesmo tempo. Os linguistas, portanto, precisarão trabalhar metodologicamente com a face concreta das entidades. É por esse motivo que entendemos a separação entre língua e fala apenas no sentido de resolver uma questão metodológica. E essa separação se dá em função de uma necessidade epistemológica: “A Linguística trabalha, pois, no terreno limítrofe em que os elementos das duas ordens se combinam; essa combinação produ₹, uma forma, não uma substância" (SAUSSURE, 1974, p. 131, grifos do autor). Ou ainda:

Sem dúvida, esses dois objetos estão estritamente ligados e se implicam mutuamente; a língua é necessária para que a fala seja inteligível e produza todos os seus efeitos, mas esta é necessária para que a língua se estabeleça; historicamente, o fato da fala vem sempre antes. [...] Enfim, é a fala que faz evoluir a língua [...]. Existe, pois, interdependência da 
língua e da fala; aquela é ao mesmo tempo o instrumento e o produto desta. Tudo isso, porém, não impede que sejam duas coisas absolutamente distintas (SAUSSURE, 1974, p. 27).

É nesse limite, portanto, que o linguista opera para poder compreender o funcionamento de uma língua, os princípios que regem esse funcionamento. Quando Saussure afirma que "Os signos de que a língua se compõe não são abstrações, mas objetos reais [...]; é deles e de suas relações que a Linguística se ocupa; podem ser chamados entidades concretas dessa ciência" (SAUSSURE, 1974, p. 119, grifos do autor), ele está delimitando onde o linguista opera e dando a noção de unidade pela identidade, pois é necessário que uma ciência tenha entidades concretas para analisar. A abstração, desta maneira, seria inconveniente para o pesquisador que deve apegar-se aos elementos concretos; abstrair seria perder de vista a abordagem metodológica do objeto. Dessa maneira, o signo carrega uma pista material, ele é representação; as entidades concretas são apenas potenciais representações, pois elas, de fato, não dizem o que é a língua, são uma ficção. A definição de signo linguístico, portanto, parte da delimitação da unidade, que nunca é dada de antemão:

\begin{abstract}
A língua não se apresenta como um conjunto de signos delimitados de antemão, dos quais bastasse estudar as significações e a disposição; é uma massa indistinta na qual só a atenção e o hábito nos podem fazer encontrar os elementos particulares. A unidade não tem nenhum caráter fônico especial, e a única definição que se pode dar a ela é a seguinte: uma porção de sonoridade que, com exclusão do que precede e do que segue na cadeia da fala, é significante de um certo conceito (SAUSSURE, 1974, p. 120, grifos do autor).
\end{abstract}

Esse é um dos diversos paradoxos que aparecem no $C L G$, questões que levam a grandes discussões, esta em particular sobre o concreto e o abstrato vemos como uma de grande complexidade no pensamento saussuriano. O que fica evidente é que a língua é um sistema e que as unidades deste são delimitadas pelo sentido, ou melhor, recortadas pelo valor, relacionadas umas com as outras que constituem este sistema em um vínculo de arbitrariedade. Em vista disso, a ideia de unidade não é a de unidade estática, pois o próprio conceito de arbitrariedade é contrário a isso. Esta permite ao mesmo tempo vínculo e afrouxamento, a mutabilidade e imutabilidade, ou seja, a língua é estática, porém inovadora, ideias que serão melhor desenvolvidas abaixo, ao abordarmos o mecanismo linguístico.

Da mesma forma, não é a materialidade que garante a identidade. Quando Saussure fala de que apenas estudar as significações e disposição não basta, é porque entendemos que a significação é o significado do signo todo, mas este temos como recuperar pelo 
dicionário, por exemplo ${ }^{7}$. Se o signo é o significado mais o significante - sendo este composto por duas partes: a realização vocal/fônica (produção e percepção); e a porção não-fônica (representação semiótica) - a entidade vocal por si só não diz nada; não é um fato linguístico, é uma massa amorfa.

Outro importante momento da reflexão saussuriana é a teoria do valor que, juntamente com o princípio de arbitrariedade, encaminha questões metodológicas. Conforme sublinhamos, a significação está na total dependência do valor. Só saberemos o valor de um signo a partir de sua relação com os demais; por essa razão, a significação de um signo isoladamente não sustenta seu valor no seio de um sistema.

Portanto, só entendemos os sentidos de um signo quando ele é colocado em relação com os demais a partir do seu emprego, ou seja, na fala. Cada ocorrência do signo é outra coisa, tem outro valor:

[...] a arbitrariedade do signo nos faz compreender melhor que o fato social pode, por si só, criar um sistema linguístico. A coletividade é necessária para estabelecer os valores cuja única razão de ser está no uso e no consenso geral: o indivíduo, por si só, é incapaz de fixar um que seja.

Além disso, a ideia de valor, assim determinada, nos mostra que é uma grande ilusão considerar um termo simplesmente como uma união de certo som com um certo conceito. Defini-lo assim seria isolá-lo do sistema do qual faz parte, seria acreditar que é possível começar pelos termos e construir o sistema fazendo a soma deles, quando, pelo contrário, cumpre partir da totalidade solidária para obter, por análise, os elementos que encerra (SAUSSURE, 1974, p. 132, grifo nosso).

Um sistema de valores negativos, como propõe Saussure, não poderia ter sido interpretado como um sistema fechado em si mesmo, já que a todo o momento existem novos cortes nas massas amorfas, portanto nada é preexistente, nada é positivo, pois só existe enquanto diferenças e negatividades. É, nesse sentido, que Saussure afirma que na língua só existem diferenças e oposições: “Todo o mecanismo da linguagem, que será tratado mais adiante, se funda em oposições desse gênero e nas diferenças fônicas e conceituais que implicam” (SAUSSURE, 1974, p. 140). É a partir daqui que o linguista vai dizer que um "fato de gramática" responde, em última análise, à definição de unidade, já que "exprime sempre uma oposição de termos", e toma como exemplo a formação do

\footnotetext{
${ }^{7}$ Evidentemente quando trazemos o exemplo do significado recuperado pelo dicionário, tomamos - como Saussure o fez - palavra como uma das possibilidades de signo na língua. Além disso, pensamos que se trata de uma ilusão dizer que podemos apreender os sentidos dados em qualquer dicionário, por essa razão mesma que a materialidade por si só não garante a identidade.
} 
plural alemão do tipo Nacht : Nächte:

Cada um dos dois termos confrontados no fato gramatical (o singular sem metafonia e sem $e$ final, oposto ao plural com metafonia e -e) está constituído por todo um jogo de oposições dentro do sistema; tomados isoladamente, nem Nacht nem Nächte são nada; logo, tudo é oposição (SAUSSURE, 1974, p. 141).

Ou seja, cada valor resulta de um conjunto de relações. A partir disso, Saussure coloca unidade e "fato gramatical" como apenas termos distintos que designam vários aspectos de um mesmo jogo de oposições linguísticas. O conceito de diferença e semelhança, ainda que pareça apenas um detalhe, permite - juntamente com a arbitrariedade - a constituição do sistema semiológico. Mais adiante no CLG, o linguista genebrino vai dizer que os valores correspondem a conceitos e que isso quer dizer que são puramente diferenciais, ou seja, são definidos negativamente por suas relações com outros termos do sistema: "Sua característica mais exata é ser o que os outros não são" (SAUSSURE, 1974, p. 136).

O que podemos concluir a partir da arbitrariedade e do valor, é que o signo só tem existência no momento de seu emprego, ou seja, é no uso efetivo, que os sujeitos realizam nas mais diversas situações de fala, que os valores se estabelecem.

É nesse sentido que podemos afirmar que, a partir da arbitrariedade do signo linguístico e da teoria do valor, a gramática em Saussure é ancorada na perspectiva da língua em emprego; não se trata, portanto, de uma gramática normativa, por exemplo. A própria ideia do mecanismo derruba qualquer associação à uma gramática que seja prescritiva-normativa, pois ele representa a língua em funcionamento, colocada em uso pelo falante.

A partir dessa breve reflexão sobre os princípios de arbitrariedade e valor, resumiremos, para o que nos concerne aqui, algumas proposições:

- A gramática em Saussure é pensada a partir de língua como sistema de signos arbitrários. Nesta só há diferenças, oposições e relações. Diferentemente da gramática comparada, Saussure vê a língua como um jogo de relações mútuas, de correspondências, de valores;

- Saussure não estava prescrevendo, pelo contrário, ele se opunha não só aos métodos da gramática comparada, mas também aos da tradicional. Ele tinha uma 
preocupação epistemológica e metodológica, não se resumindo a isso, evidentemente. No entanto, é essa preocupação que vai levar Saussure a pensar sobre os dois princípios fundamentais de uma gramática, diremos sincrônica: a arbitrariedade e o valor, que resolvem um problema metodológico - ajudando a fundar a Linguística como ciência, delimitando e entendendo a unidade a partir da compreensão desses dois princípios;

- A arbitrariedade e o valor são dois princípios que nos levam a entender a gramática em Saussure na perspectiva da língua em uso. Se a língua tem, ao mesmo tempo, caráter de fixidez (imutabilidade) e de inovação (mutabilidade), e isso ocorre por intermédio das relações no sistema da língua, um sistema de valores, é, portanto, no exercício da linguagem através da língua - a fala - que isso se concretiza de alguma forma; é a coletividade que cria o valor. É, portanto, no ato de fala que veremos o funcionamento da língua. A partir do momento em que esta é virtual (essa tentativa de comungarmos valores) é por meio da fala que colocamos os elementos em relação, entendendo a fala como apropriação individual da língua.

\section{Mecanismo linguístico: o aspecto estático e criativo da língua}

Saussure divide a linguística a partir de dois pontos de vista: o sincrônico e o diacrônico. Sabemos que o ponto de vista é que cria o objeto, como explicitado anteriormente; em vista disso, há vários pontos de vista sobre a língua: filosófico, fisiológico, antropológico, sociológico, etc. A partir do ponto de vista da Linguística, conforme o CLG, existem duas formas de olhar para a língua: o diacrônico ou histórico, ou seja, do ponto de vista de sua evolução no tempo; e o sincrônico ou estático, ou seja, o estado de uma língua, tendo em conta um determinado momento. É a partir disso que o linguista genebrino discorre sobre duas relações que são chamadas de sintagmáticas e associativas. Após isso, ele traz o funcionamento dessas relações, defendendo a ideia de uma Linguística estática, expondo sua concepção de gramática nos termos da sincronia. Já na parte dita diacrônica do CLG é que aparece um princípio que ao mesmo tempo é o responsável pela regularidade e pelas inovações das línguas: a analogia. Isso faz parte do que Saussure chama de mecanismo, que é o modo de funcionamento das línguas. É entre os eixos sintagmático e associativo que operam os princípios de arbitrariedade e de valor, uma vez que é através das relações sintagmáticas e associativas que um elemento ganha valor no sistema. 
Conforme apontamos anteriormente, o mecanismo da língua é um dos temas mais complexos do legado do mestre. Para a linguística de seu tempo, o que interessava era o estudo diacrônico da língua. Saussure não ignora esse fazer, já que ele também se forma como linguista a partir desse ponto de vista, mas mostra como não é somente o fato histórico que constitui uma língua:

A verdade sincrônica contradiz acaso a verdade diacrônica, e será mister condenar a Gramática tradicional em nome da Gramática histórica? Não, pois isso seria ver a realidade pela metade; não se deve pensar que somente o fato histórico importa e que basta para constituir uma língua (SAUSSURE, 1974, p. 113).

Ademais, Saussure coloca a diacronia definindo a sincronia, justificando sua escolha também a partir do sujeito falante:

Se a língua tem um caráter de fixidez, não é somente porque está ligada ao peso da coletividade, mas também porque está situada no tempo. Ambos os fatos são inseparáveis. A todo instante, a solidariedade com o passado põe em xeque a liberdade de escolher. Dizemos homem e cachorro porque antes de nós se disse homem e cachorro. Isso não impede que exista no fenômeno total um vínculo entre esses dois fatores antinômicos: a convenção arbitrária, em virtude da qual a escolha se faz livre, e o tempo, graças ao qual a escolha se acha fixada (SAUSSURE, 1974, p. 88, grifos do autor).

Logo, Saussure interessa-se pela linguística sincrônica, em que definirá sua gramática, porém jamais ignora o outro ponto de vista, pelo contrário, o próprio fenômeno da analogia implica o caráter histórico para se chegar a um estado de língua; os dois pontos de vista estão implicados, no entanto, Saussure atém-se à sincronia, por ser este o ponto em que acreditamos que o mestre genebrino funda a sua gramática e o fazer do linguista.

Para chegarmos ao fenômeno linguístico que escolhemos - a analogia - é necessário que antes pensemos sobre algumas questões teóricas e metodológicas da reflexão saussuriana sobre identidades, realidades e valores. $\mathrm{Na}$ segunda parte da Linguística sincrônica, no capítulo III, aparece essa discussão no CLG. Saussure se faz duas perguntas e uma constatação a partir disso: a) O que é uma identidade sincrônica?; b) O que é uma realidade sincrônica? Que elementos concretos ou abstratos da língua podem ser assim chamados?; e c) Por fim, todas as noções versadas não diferem essencialmente daquilo que chamamos de valores. Este capítulo segue a discussão sobre as unidades da língua, porém, agora, colocando o mecanismo em jogo: "O mecanismo linguístico gira todo ele sobre identidades e diferenças" (SAUSSURE, 1974, p. 126). 
Quanto à primeira pergunta, de novo temos uma questão que gira em torno da materialidade e também do valor de uma identidade sincrônica. Para ilustrar o que seria uma identidade sincrônica, o genebrino utiliza o exemplo da (repetição) da palavra "Senhores?", o de dois expressos "Genebra-Paris, 8h45 da noite" e o da rua reconstruída. Aparentemente, a repetição da primeira nos faz perceber que se trata sempre da mesma expressão, no entanto, há variações de entonação, de volume, etc.; os dois expressos que partem com $24 \mathrm{~h}$ de intervalo parecem os mesmos, no entanto, as pessoas, os vagões são distintos; no caso da rua arrasada, quando reconstruída, ela parecerá a mesma rua, embora materialmente nada da antiga tenha sido preservado. O que está em jogo aqui são justamente os valores, cada vez que "Senhores?" é dito, que os dois expressos partem e que a rua é reconstruída

[...] eu lhe renovo a matéria; é um novo ato fônico e um novo ato psicológico. O vínculo entre os dois empregos da mesma palavra não se baseia na identidade material nem na exata semelhança de sentido, mas em elementos que cumprirá investigar e que nos farão chegar bem perto da verdadeira natureza das unidades linguísticas (SAUSSURE, 1974, p. 126-127).

Com relação à segunda pergunta, Saussure vai dizer que se trabalha com conceitos forjados pelos gramáticos, que classificam as palavras em substantivos, adjetivos, verbos, etc.; essa não é, segundo o linguista genebrino, uma realidade que se possa negar, porém ele vai dizer que "as entidades concretas da língua não se apresentam por si mesmas à nossa observação" e que, além disso, "não existem fatos linguísticos independentes de uma matéria fônica dividida em elementos significativos" (SAUSSURE, 1974, p. 127-128), ou seja, de novo o que está em jogo é o valor. Em vista disso, é que ele chega ao ponto C: todas essas noções são, essencialmente, o que chamamos valores. É o aspecto primordial para entendermos identidades e realidades sincrônicas, visto que o mecanismo linguístico gira ao redor de identidades e diferenças, pois

Via de regra, não falamos por signos isolados, mas por grupos de signos, por massas organizadas, que são elas próprias signos. Na língua tudo se reduz a diferenças, mas tudo se reduz também a agrupamentos. Esse mecanismo, que consiste num jogo de termos sucessivos, se assemelha ao funcionamento de uma máquina cujas peças tenham todas uma ação recíproca, se bem que estejam dispostas numa só dimensão (SAUSSURE, 1974, p. 149).

Trata-se de dois tipos de relações, a sintagmática e a associativa. Se num estado de língua tudo se baseia em relações, de que forma elas funcionam? O linguista genebrino vai dizer que cada uma delas gera certa ordem de valores e que elas correspondem às duas 
formas de nossa atividade mental, sendo imprescindível para a vida da língua.

As relações sintagmáticas são baseadas no caráter linear da língua (que é o caráter do significante do signo), os elementos se alinham um após o outro na cadeia da fala. É neste momento em que aparecem as noções de sintagma e frase; aquela sendo aplicada não só a palavras, mas a grupos de palavras e outras unidades mais complexas e extensas, atribuindo à língua todos os tipos de sintagmas construídos sobre formas regulares; e a frase sendo colocada como o tipo de sintagma por excelência, pertencendo à fala, pois é à fala que se atribui a liberdade de combinações. É, nesse sentido, que o linguista exemplifica, então, que é possível que uma palavra como indecorável seja construída, pois existem números suficientes de palavras semelhantes que pertencem à língua, como inquestionável, intragável, imperdoável, etc. Logo, a relação sintagmática - assim como a associativa, como veremos - permite-nos construir novos elementos, expressões sobre padrões regulares a partir de recordações concretas que têm base na língua (por analogia).

Já as relações associativas não se limitam a aproximação de elementos em comum, mas também a tudo aquilo que possa ser evocado e que seja suscetível de ser-lhe associado de uma forma ou de outra. A figura utilizada de exemplo no CLG é a de uma constelação da palavra "ensinamento" em que aparecem ramos representando essas associações possíveis da palavra (SAUSSURE, 1974, p. 146). Ao contrário das relações sintagmáticas, as associativas podem ser de "ordem indeterminada e número indefinido", e é essa indefinição que nos leva à arbitrariedade radical. As duas relações - as duas formas de agrupamento ocorrem simultaneamente e colocam em relevo o falante em relação com a língua. Ou seja, a ideia evoca todo um sistema latente, obtendo-se oposições necessárias à constituição do signo; mudando-se a ideia, outras oposições serão necessárias para fazer aparecer outro valor. São essas relações simultâneas, associativas e sintagmáticas, que aparecem e estão em jogo no sistema da língua.

É nesses termos, portanto, que, no CLG, encontramos a questão da analogia como um fenômeno sincrônico. Antes de entrarmos na analogia propriamente dita, queremos retomar a reflexão saussuriana sobre o mecanismo, especificamente na discussão das subdivisões da gramática. O capítulo começa falando sobre a Linguística estática ou descrição de um estado de língua, que nada mais é que a visão sincrônica da língua, ou gramática (SAUSSURE, 1974, p. 156). Saussure vai dizer que gramatical significa sincrônico e significativo. O texto é dividido em "Definições: divisões tradicionais", em que há uma 
crítica à gramática dita tradicional; e "Divisões racionais", em que é proposta uma nova subdivisão. Por que seria importante falar de divisões na gramática? Pois é neste ponto em que vemos o linguista genebrino mostrando a importância de se estudar as questões gramaticais a partir de um duplo ponto de vista: associativamente ou sintagmaticamente:

Seria necessário poder reduzir dessa maneira cada fato à sua ordem, sintagmática ou associativa, e condenar toda a matéria da Gramática sobre esses dois eixos naturais; somente essa repartição mostraria o que cumpre mudar nos quadros usuais da Linguística sincrônica (SAUSSURE, 1974, p. 159).

Além disso, há uma crítica à exclusão da lexicologia na divisão da gramática tradicional. O termo gramática, em Saussure, portanto, engloba a lexicologia e além disso coloca a morfologia e a sintaxe como interdependentes: "Linguisticamente, a morfologia não tem objeto real e autônomo; não pode constituir uma disciplina distinta da sintaxe" (SAUSSURE, 1974, p. 157); assim como a lexicologia não dá conta do sentido sem o estudo gramatical. O princípio que faz da língua um sistema de valores se aplica da mesma maneira aos elementos gramaticais e lexicais; não faria nenhum sentido manter uma subdivisão de gramática em que se estuda separadamente a morfologia, a sintaxe e a lexicologia em uma noção de língua em que esta constitui um sistema de diferenças significativas, onde a própria noção de valor põe em relação os elementos desse sistema. As oposições gramaticais e lexicais não se separam do uso.

A analogia, então, é um fenômeno pelo qual Saussure consegue, desveladamente, mostrar ao mesmo tempo o caráter estático e o caráter criativo da língua. Em um mesmo fenômeno, podemos concluir não só que por meio dele acontecem eventos regulares, mostrando o aspecto de fixidez da língua, mas também que existem inovações.

Para o fenômeno analógico, Saussure traz um esquema que ele chama de cálculo da quarta proporcional. Em termos matemáticos (que é de onde Saussure, evidentemente, tira essa expressão) seria encontrar um quarto elemento proporcional a outros três elementos, como uma regra de três. O mestre genebrino é bastante perspicaz nessa comparação, pois a ideia de ser proporcional é exatamente a ideia da analogia ser um fenômeno que "supõe um modelo e sua imitação regular. Uma forma analógica é uma forma feita à imagem de outra ou de outras, segundo uma regra determinada" (SAUSSURE, 1974, p. 187, grifo do autor). O exemplo do qual o linguista genebrino se serve é do nominativo latino bonor: "A princípio se disse honōs: honōsem, depois por rotacismo do s, honōs: honōrem. O radical tinha, desde então, uma forma dupla; tal dualidade foi eliminada pela nova forma honor, criada sobre o modelo de 
orator: oratorem etc [...]" (SAUSSURE, 1974, p. 187). Isto é, o fenômeno analógico atua em favor da regularidade e busca guiar os processos de renovação linguística.

Se a analogia é um fenômeno que tende à regularidade, o que leva Saussure, então, a concluir que este mesmo fenômeno também é um aspecto de inovação da língua? A resposta está numa simples troca de termos. O mestre genebrino não usa o termo mudança para referir-se ao fenômeno analógico, assim como se utiliza para mudanças fonéticas. F. de Saussure não vê a analogia como uma anomalia ou engano, tampouco como simples mudança, pois não se trata de uma mera mudança fonética; ele vai além e afirma ser uma inovação analógica. Ademais, uma inovação é diferente de eliminação da forma antiga, já que em algum momento esta e a forma nova coexistiram. Portanto, ainda que o fenômeno da analogia seja em favor da regularidade - pois é a partir de um modelo que ele se estabelece - é também uma criação, já que é “[...] precedida de uma comparação inconsciente dos materiais depositados no tesouro da língua, em que as formas geradoras se alinham de acordo com suas relações sintagmáticas e associativas" (SAUSSURE, 1974, p. 192, grifo nosso). Essas relações estão representadas na fórmula quarta proporcional, já que é necessário invocar formas já existentes para explicar o aparecimento de outra; associamos, portanto, determinadas combinações com outras para poder demonstrar o fenômeno.

No fenômeno analógico, portanto, podemos enxergar todo um jogo de relações (associativas e sintagmáticas) que se explicam através da arbitrariedade e do valor. Numa construção como indecorável, existe, mesmo antes de ser evocada, um potencial de criação, visto que no sintagma encontramos construções semelhantes com os mesmos prefixos e sufixos. Ademais, associativamente, fazemos relações com termos e elementos semelhantes (e dessemelhantes) da língua. O que permite que a analogia seja, portanto, uma criação dos princípios da arbitrariedade e do valor, já que, conforme o arbitrário radical, qualquer massa amorfa de sons pode ligar-se a um sentido; e o que permite a existência de tal termo é que ele seja colocado em oposição e diferença, ou seja, negativamente, com outros elementos do sistema. A esse respeito, Saussure cita o exemplo das criações presentes nas falas infantis:

A operação de analogia é mais viva e mais fértil na criança porque sua memória ainda não teve tempo de armazenar um signo para cada idéia e, por conseguinte, ela se vê obrigada a confeccionar, a cada instante, esse signo. Ora, ela o fabricará sempre de acordo com o procedimento de analogia (SAUSSURE, 2004, p. 140).

Dessa forma, a analogia é um fenômeno que mostra que a língua, por um lado, é 
contínua, não muda: "Nesse sentido, pode-se dizer que a analogia, precisamente porque utiliza sempre a matéria antiga para as suas inovações, é eminentemente conservadora" (SAUSSURE, 1974, p. 200); por outro lado, também mostra que a língua evolui:

De fato, a história de cada língua permite descobrir um formigueiro de fatos analógicos acumulados uns sobre os outros, e, tomados em bloco, esses contínuos reajustes desempenham um papel considerável na evolução da língua, mais considerável, inclusive, que o das mudanças de sons (SAUSSURE, 1974, p. 199).

Estes dois princípios resolvem questões metodológicas e permitem que depreendamos um conceito de gramática. Dessa forma, podemos resumir aqui esta seção em algumas proposições:

- Saussure afirma que qualquer ponto de gramática mostraria a importância de estudar cada questão a partir do duplo ponto de vista, ou seja, sintagmaticamente e associativamente. A analogia acaba sendo o grande exemplo dado no CLG de como se deve analisar um fato gramatical através desses dois pontos;

- O mecanismo da língua mostra-nos que a gramática pensada por Saussure é a partir da perspectiva da língua em uso, ao contrário do que por muitas décadas se pensou, que o linguista genebrino renega o sujeito falante. Entendemos, a partir do mecanismo, que a analogia é o grande exemplo de como o sujeito falante e a fala estão, sim, presentes na reflexão saussuriana, colocando como indissociáveis da análise linguística, já que a analogia só acontece porque há um grupo/uma sociedade pela qual a língua funciona e toma existência. A analogia coloca em relevo o sujeito falante em relação com a língua. Existe, nesse sentido, um lugar para a criatividade que vem pela fala e se estabelece no sistema da língua;

- Por trás do fenômeno analógico e, portanto, do mecanismo, enxergamos dois princípios fundamentais que regem não só a analogia em si, mas também o conceito de gramática em Saussure: a arbitrariedade e o valor. São estes dois grandes princípios que marcam/definem as relações dos eixos sintagmático e associativo;

- A gramática em Saussure é uma gramática que comporta a lexicologia da mesma forma que a morfologia e a sintaxe. Estas subdivisões da gramática são vistas pelo mestre genebrino inter-relacionadas. Não é possível pensar cada uma isoladamente, pois seria difícil, por exemplo, entender o sentido de uma palavra, no nível morfológico, sem pensar no nível da sintaxe. Estas subdivisões deveriam ser vistas 
relacionadas e não de maneira isolada;

- O conceito de gramática que podemos depreender a partir do legado saussuriano é um conceito desde a perspectiva da Linguística sincrônica/descritiva; é pelos estados de língua que se estabelecem as diversas relações que atribuem à gramática, embora isso signifique, de certa forma, simplificar os dados ou, ainda, ser reducionista como o próprio genebrino admite. Não existe uma "Gramática histórica", existe uma Linguística diacrônica, embora ela seja definidora do estado em que se encontra uma língua;

- Acreditamos que com isso, Saussure não tinha apenas uma preocupação/necessidade metodológica, ou seja, de encontrar métodos que pudessem fundar a Linguística como ciência, pensando, sobretudo no que o linguista faz (e para tanto definir o objeto de análise), mas também criar uma nova epistemologia, pois Saussure reflete sobre a natureza semiológica da língua, sobre o conhecimento e suas relações entre o sujeito e o objeto em questão, e com isso funda uma nova epistemologia da Linguística.

\section{Considerações finais}

Vimos, ao longo de nosso percurso, como a arbitrariedade, o valor e o mecanismo fundam a noção de gramática em Saussure. Os dois primeiros são princípios que constituem não só o signo linguístico, mas também (e por isso) regem as relações (sintagmáticas e associativas) implicadas no mecanismo da língua. O fenômeno analógico é o grande exemplo gramatical dentre outros (assim como a etimologia popular ou a aglutinação) em que o mestre genebrino consegue demonstrar o mecanismo da língua a partir do que ele chama de duplo ponto de vista, ou seja, das relações sintagmáticas e associativas.

Por meio deste fenômeno, Saussure também consegue explicitar como a arbitrariedade e a teoria do valor são fundamentais para entender o fenômeno em si. Tudo gira em torno desses dois princípios que fundamentam o conceito de gramática em Saussure. Uma gramática sincrônica, que não relega a Linguística histórica, pelo contrário, reconhece seu fazer e a coloca como definidora do estado de língua passível de análise pelo linguista, atrelada ao princípio do arbitrário e ao jogo de valores que este induz, via 
mecanismo.

Finalmente, cabe dizer que foi justamente a partir de uma preocupação epistemológica e metodológica que o mestre genebrino acabou empreendendo uma reflexão que envolveu pensar sobre como a língua funciona. E foi por não ter deixado de lado a ação da massa de falantes sobre a língua que os princípios de arbitrariedade, valor e mecanismo redundaram em sua noção de gramática. Vale dizer também que nossa reflexão não encerra a discussão sobre gramática em Saussure; afinal, o retorno à leitura atenta da herança do mestre se fará sempre necessário, como bem lembra Normand (2009).

\section{Referências}

BENVENISTE, Émile. Saussure após meio século. In: Problemas de linguística geral I. Campinas: Pontes Editores, 1991, p. 34-59.

FLORES et al. Saussure: a invenção da linguística (Org.). São Paulo: Contexto, 2013.

GADET, Françoise. Saussure: une science de la langue. 2 ed. Paris: Presses Universitaires de France, 1990.

NORMAND, Claudine. Saussure. Trad. Ana de Alencar e Marcelo Diniz. São Paulo: Estação Liberdade, 2009.

SAUSSURE, Ferdinand de. Curso de linguística geral. 8 ed. São Paulo: Cultrix, 1974.

Escritos de linguística geral. Organizados e editados por Simon Bouquet e Rudolf Engler com a colaboração de Antoinette Weil. Trad. Carlos Augusto Leuba Salum e Ana Lucia Franco. São Paulo: Cultrix, 2004. 


\section{Abstract}

This text presents and develops the idea concerning the notion of grammar in Saussure, based on three essential principles, namely arbitrariness, value, and the linguistic mechanism. We aim to show how these three principles establish a concept of grammar in Saussure. Initially, we discuss the development of the author's line of thought by resolving a methodological issue based on the first two principles - arbitrariness and value. Our reading of the Course in General Linguistics enables us to extract these notions, which then lead us to the conclusion that it is possible to perceive the functioning of language in its use. Finally, we show how arbitrariness and value are at stake in the linguistic mechanism. We understand that analogy, one of the phenomena that explain the linguistic mechanism, is the main example of how the speaker and the notion of parole [speech] itself are present in the Saussurean perspective. Therefore, the conception of grammar in Saussure stems from these three major principles that are interconnected.

Keywords: Arbitrariness. Epistemology of linguistics.

Grammar. Mechanism. Linguistic value

Recebido em: 19/04/2018.

Aceito em: 02/07/2018. 